\title{
Effect of Carbon Ash Content on the Thermal and Combustion Properties of Waste Wood Particle / Recycled Polypropylene Composites
}

\author{
Kuo-Wei CHEN ${ }^{1, a^{*}}$, Ta-Hsiang HU ${ }^{1, b}$, Yuan-Shing PERNG ${ }^{2, \mathrm{c}}$ and Ching-Shun $\mathrm{CHEN}^{2, \mathrm{~d}}$ \\ ${ }^{1}$ Department of Electrical Engineering, Da-Yeh University, 168 University Rd, Dacun, Changhua, \\ 51591, Taiwan(R.O.C.) \\ ${ }^{2}$ Department of Environmental Engineering, Da-Yeh University, 168 University Rd, Dacun, Changhua, \\ 51591, Taiwan(R.O.C.) \\ *aaa5433.zkhn@gmail.com \\ b thhu@mail.dyu.edu.tw \\ cysperng@mail.dyu.edu.tw \\ dcschen@mail.dyu.edu.tw
}

\begin{abstract}
This study effect of carbon ash content on the thermal stability and combustion behavior of waste wood particle / recycled polypropylene composites was investigated using TGA, DTG, LOI and cone calorimeter. The TGA shows that, as carbon ash content increases, the thermal stability of composites increases, while the residual weight significantly increases, with the residual weight rate of waste wood particle / recycled polypropylene composites increases from $13.97 \%$ to $41.02 \%$ at $800^{\circ} \mathrm{C}$; According to cone calorimeter results, in the $50 \mathrm{~kW} / \mathrm{M} 2$ thermal flow, when carbon ash adding to $70 \%$, peak heat release rate and total heat release quantity, decreases by $68 \%$ and $52 \%$, respectively. The LOI of waste wood particle / recycled polypropylene composites improves by about 34\%, Conforming UL-94 flammability standard, V-0 rating. The residual weight rate increases by $202.8 \%$, which the significant role of carbon ash in flame retardant.
\end{abstract}

\section{Introduction}

Production of waste reuse composite materials using waste wood particle and waste polypropylene is a very important area of research study direction. In recent years, applications of waste reuse composite materials presented by the changing trends in industrial applications to home building materials and furniture materials. But composite

\footnotetext{
* Corresponding author: aa5433.zkhn@gmail.com
} 
materials made of waste wood and waste polypropylene is flammable materials used in home space must have its security concerns. [1][2]

From the point of combustion processes and pyrolysis of combustible materials, the solid combustible materials can be divided into coking and non-coking type two categories. Non-coking type combustible material can be almost completely burned, do not residues exist, such as polypropylene, polyethylene ... etc. Coking combustible material in the combustion process produces carbon layer on the surface, the carbon layer will hinder thermal conduction and flash fire, a temperature gradient within the material, and further affect the rate of pyrolysis and burning.

The pyrolysis and combustion characteristics of wood and polypropylene in domestic and overseas has been a considerable number of studies and the establishment of a variety of combustion model. However, past research is limited to new materials (first raw) instead of recycling old material. In this study, the production of waste recycled wood, carbon ash and polypropylene, but the recycling of waste materials has characteristics instability, so the recycling of waste materials substances cannot apply the same with the new materials.

Current literature waste composite board made for combustion and flame retardant effectiveness evaluation is very rare. In this study, using thermal gravimetric analysis and calorimeter for different levels of carbon ash composites studied the thermal stability and combustibility, and to master the thermal characteristics of composite materials, and for reasonable study retardant processing laid the theoretical foundation.[3][4][5]

\section{Research Methods}

In order to cope with the new pyrolysis system, the physical properties of the catalyst need to be adjusted appropriately. The new pyrolysis system has three modes of operation, including the economic model, standard mode and overdrive mode. The new pyrolysis system operating mode selection determines the type of the catalyst. Catalyst choices are shown in Table 1.

Table 1 Characteristics Of Operation Mode

\begin{tabular}{|c|c|c|c|}
\hline Operation mode & Economic mode & Standard mode & Overdrive mode \\
\hline Catalyst & B13AR 1 & B13AR3 & B13AR2 \\
\hline Operation Temperature & $370{ }^{\circ} \mathrm{C}$ & $390{ }^{\circ} \mathrm{C}$ & $415^{\circ} \mathrm{C}$ \\
\hline Green diesel output & $27 \%$ & $34 \%$ & $46 \%$ \\
\hline Carbon black output & $38 \%$ & $31 \%$ & $25 \%$ \\
\hline Green diesel quality & Good, yield less & Normal & Very good, yield more \\
\hline Carbon black quality & Very Good & Acceptable & Very poor \\
\hline $\begin{array}{c}\text { Carbon content of carbon } \\
\text { black }\end{array}$ & $97 \sim 99 \%$ & $95 \sim 90 \%$ & $68 \sim 52 \%$ \\
\hline Catalyst Producer & Our laboratory & ZKHN Ltd & Our laboratory \\
\hline
\end{tabular}

In the overdrive mode of operation, the carbon ash produced by the very low carbon content and quality is very poor. Carbon ash is no commercial value in this market, must be treated as waste, not only need to pay removal costs, also contributed to rising corporate operating costs. Therefore, this study is the use of composite materials to the carbon ash. The waste wood particle, carbon ash and recycled polypropylene of particles hot pressing forming. 
Table 2 Waste Wood Particle / Recycled Polypropylene Composite Formulation

\begin{tabular}{|c|c|c|c|}
\hline Formulation & Waste wood particle & Carbon ash & Recycled polypropylene \\
\hline ZK00 & $90 \%$ & $0 \%$ & $10 \%$ \\
\hline ZK30 & $60 \%$ & $30 \%$ & $10 \%$ \\
\hline ZK50 & $40 \%$ & $50 \%$ & $10 \%$ \\
\hline ZK70 & $20 \%$ & $70 \%$ & $10 \%$ \\
\hline ZK90 & $0 \%$ & $90 \%$ & $10 \%$ \\
\hline
\end{tabular}

\section{Results and Discussion}

\subsection{Limiting Oxygen Index Test and Vertical Flame Test Results}

As can be seen from Table 3, the limiting oxygen index(LOI) of the Waste Wood Particle / Recycled Polypropylene Composites increases with the increase of the added amount of carbon ash. When carbon ash mass fraction of $90 \%$, the limiting oxygen index was $32.7 \%$, up $42.8 \%$ over the composition without adding carbon ash, flame retardant property effect is very significant.

Table 3 Limiting Oxygen Index Test And Vertical Flame Test Results Composites

\begin{tabular}{|c|c|c|}
\hline Formulation & Limiting oxygen index \% & UL-94 \\
\hline ZK00 & 22.9 & -- \\
\hline ZK30 & 25.7 & V-2 \\
\hline ZK50 & 28.3 & V-1 \\
\hline ZK70 & 30.6 & V-0 \\
\hline ZK90 & 32.7 & V-0 \\
\hline
\end{tabular}

\subsection{Thermal Stability of Carbon Ash Content for Waste Wood Particle / Recycled Polypropylene Composites}

TGA and DTG curves of different carbon black content of the composite, as shown in Figure 1 and Figure 2. The initial temperature of the pyrolysis temperature and the maximum rate of weight loss are shown in Table 4.

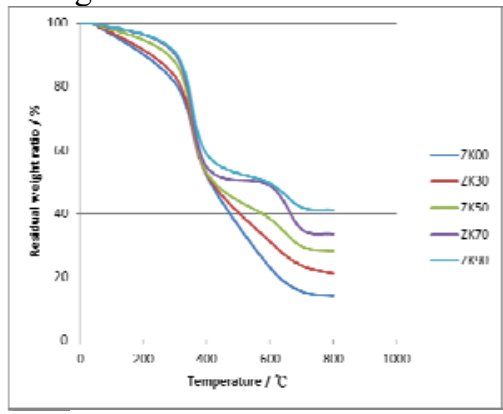

Fig 1 TGA

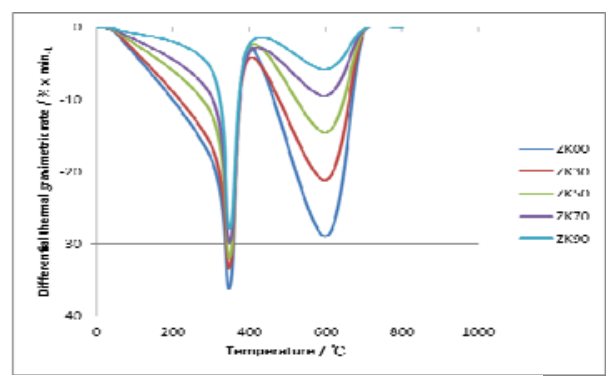

Fig 2 DTG 
Table 4 The Results Of Different Carbon Ash Content Of Waste Wood Particle / Recycled Polypropylene Composite Materials In Tga And Dtg Testing

\begin{tabular}{|c|c|c|c|}
\hline Formulation & $\begin{array}{c}\text { TGA } \\
\mathrm{T}_{0} /{ }^{\circ} \mathrm{C}\end{array}$ & $\begin{array}{c}\mathrm{DTG} \\
\mathrm{T}_{\mathrm{p}} /{ }^{\circ} \mathrm{C}\end{array}$ & $\begin{array}{c}\text { Residual weight rate } \\
\text { in } 800{ }^{\circ} \mathrm{C}\end{array}$ \\
\hline ZK00 & 66.8 & $373.9 / 497.2$ & 13.97 \\
\hline ZK30 & 83.4 & $377.1 / 501.3$ & 20.99 \\
\hline ZK50 & 100.8 & $381.6 / 517.9$ & 28.02 \\
\hline ZK70 & 137.2 & $396.7 / 534.8$ & 33.47 \\
\hline ZK90 & 189.6 & $400.3 / 558.9$ & 41.02 \\
\hline
\end{tabular}

Note: $\mathrm{T}_{0}$ refers to the decomposition temperature of the sample at $1 \% ; \mathrm{T}_{\mathrm{p}}$ refers to the weight loss rate that corresponds to the peak temperature

Figure 1 and Table 2 can be found, ZK00 is very easy to burn, thermal decomposition products contain volatile components, although there are generating solid carbide, but the charring of performance is not significant. ZK00 because contains $10 \%$ polypropylene, although the combination of wood particle and polypropylene, but both are part of flammable substances, thus reducing the thermal decomposition stability. ZK00 ZK70 the thermal stability test, a total of two peaks. The first peak is the peak thermal weight loss of wood, with the increase in the ash content, the thermal stability of the composite increased significantly. The Water adsorption of wood particle, other molecules compounds or hemicellulose, so when the first heat decomposition, so that the wood particle is less stable. When the temperature is below $110^{\circ} \mathrm{C}$, there is a significant loss of weight.

The second peak is the peak of carbon ash TGA, Carbon black composition contains about $60 \%$ fixed carbon and $40 \%$ ash (Inorganic, non-combustible material). Thus increase in carbon ash content, TP relatively gradual increase. For the generation of carbon significantly improved performance and combustion characteristics are significant for delaying action. With the increase of the added amount of carbon ash, the maximum decomposition temperature of the composite material is increased. When the mass fraction of $70 \%$ carbon ash when, T upgrade from 66.8 to 137.2 , T raised to 396.7 from 373.9 , improved $6 \%$, T raised to 534.8 from 497.2 , improved $7.6 \%$.

\subsection{Ignition Time of Carbon Ash Content}

As can be seen from Table 5, with increasing carbon black content, ignition time is gradually longer. When the mass fraction of carbon ash is $50 \%$, the composite material is resistant to significantly improve the ignition time, the mass fraction of carbon ash is increased to $90 \%$, the composite material to improve the ignition time resistance of $137 \mathrm{sec}$. Carbon ash is mainly composed of carbon, ash, flame retardant material, composed of inorganic and other polymers. In composite materials, carbon ash and wood particle fully bonded, so ignite the process, because the silicon oxide, flame retardant material release $\mathrm{CO}$, the composite material is not easy to ignite.

Table 5 Waste Wood Particle / Recycled Polypropylene Composite Cone Calorimeter Analysis Of Data

\begin{tabular}{|c|c|c|c|c|c|c|}
\hline Formulation & $\begin{array}{c}\text { Ignition time } \\
(\mathrm{sec})\end{array}$ & $\begin{array}{c}\text { Peak heat } \\
\text { release rate / } \\
\left(\mathrm{kW} \cdot \mathrm{m}^{-2}\right)\end{array}$ & $\begin{array}{c}\text { The total } \\
\text { heat release } \\
(450 \mathrm{Sec}) / \\
\left(\mathrm{MJ} \cdot \mathrm{m}^{-2}\right)\end{array}$ & $\begin{array}{c}\text { The total } \\
\text { smoke } \\
\text { release }(450 \\
\mathrm{Sec}) / \\
\left(\mathrm{MJ} \cdot \mathrm{m}^{-2}\right)\end{array}$ & $\begin{array}{c}\text { Continuous } \\
\text { burn time / } \\
(\mathrm{Sec})\end{array}$ & $\begin{array}{c}\text { Residual } \\
\text { weight } \\
\text { rate }\end{array}$ \\
\hline ZK00 & 39 & 362.4 & 118.5 & 17.8 & 543 & 11.23 \\
\hline ZK30 & 48 & 207.9 & 89.5 & 15.2 & 697 & 18.79 \\
\hline ZK50 & 74 & 163.5 & 73.9 & 14.3 & 786 & 26.57 \\
\hline ZK70 & 98 & 114.7 & 57.2 & 12.4 & 834 & 32.04 \\
\hline ZK90 & 137 & 89.2 & 43.7 & 9.2 & 1187 & 39.98 \\
\hline
\end{tabular}




\subsection{Heat Release Rate of Carbon Ash Content}

Control samples ZK30 ZK90, with the mass fraction of carbon ash is increased, the heat release rate decreased significantly, from $207.9 \mathrm{~kW} / \mathrm{m} 2$ reduced to $89.2 \mathrm{~kW} / \mathrm{m} 2$. Because carbon ash thermal decomposition of non-combustible gas containing silicon oxide and carbon ash influence. Produced in the surface protective layer (silicon oxide layer and charring layer) impede combustion, so that the heat release rate is reduced.

\subsection{The Total Heat Release Effect}

Total heat release value of the material is smaller, the better the flame retarding effect of materials. As apparent from Table 5, the flame combustion stage, without adding carbon ash composite material, at 450 seconds, the total heat release up to $118.5 \mathrm{MJ} . \mathrm{m}^{-2}$. But $30 \%$ of the carbon ash, at 450 seconds, the total heat release was reduced to $89.5 \mathrm{MJ} . \mathrm{m}^{-2}$, when the amount of carbon ash is added to $90 \%$ in 450 seconds; the total heat release is more reduced to $43.7 \mathrm{MJ} . \mathrm{m}^{-2}$. Because the carbon ash contains large amounts of non-combustible components, and silicon oxide cannot participate in the combustion, so that the greater the mass fraction of carbon ash is added, will help to reduce the total heat release. And carbon ash in high temperature combustion process, sustained release of non-combustible gas, so the flame retardant composite materials has its positive help.

\subsection{The Total Smoke Release Effect}

Combustion process the less smoke release, higher material security, so better flame retardant properties. Table 5 shows that adding carbon ash at $30 \%$ of the total emission of smoke was significantly lower than the composites without added carbon ash. In 450 seconds, the total smoke emission by $17 \%$. When the carbon ash content was $90 \%$, the total smoke release composites significantly reduced to $9.2 \mathrm{MJ} . \mathrm{m}^{-2}$. Therefore, the addition of carbon ash, composite materials will help reduce total smoke emission. Mainly because carbon ash itself has a lot of silicon oxide, a flame retardant effect, and the combustion process releases non-flammable gas for combustion behavior inhibition, so that the total effective in reducing smoke emissions.

\subsection{Residual Carbon Content after Burning}

As seen in Table 5, the content of carbon black added is increased, the mass loss of the composite material decreases and increase of the combustion time. On the basis of past experience under the mass loss smaller and longer combustion conditions better flame retardant properties. This research found that when the complete combustion of the carbon ash composite material without added weight residue was $11.23 \%$, addition of carbon ash is $30 \%$, the residual weight rate of $18.79 \%$, compared with the sample without the added carbon ash is improved by $67.3 \%$. When added to the carbon ash content of $90 \%$, the residual weight composite material was $39.98 \%$ Therefore, the addition of carbon black to improve weight of residue is significant.

\section{Conclusions}

TGA results show that with the increase of carbon ash content, the thermal stability of the waste wood particle / recycled polypropylene composites to enhance and residual carbon 
significantly increased, when $800^{\circ} \mathrm{C}$, increased from $11.23 \%$ to $39.98 \%$. And can prove carbon ash added to the waste wood particle / recycled polypropylene composites properties including heat release, smoke and residual carbon rate of release of its significant impact, for composite materials with a strong flame retardant and smoke suppression effect.

When adding carbon ash mass fraction of $50 \%$, the combustion parameters to improve the already very significant, significant increase flame retarding effect composites. However, the carbon ash content of $90 \%$, the residual weight rate and flame retarding effect has significantly increased, but when the carbon ash content exceeds $70 \%$, the content of the wood particle has been less than $20 \%$, the overall mechanical properties of the waste wood particle / recycled polypropylene composites has a large the magnitude of the downward trend. So, considering the overall performance and mechanical properties of waste wood particle / recycled polypropylene composites, when carbon black mass fraction of $70 \%$, the performance in the composite properties of the balance. Carbon ash is mainly composed of carbon, ash, flame retardant material, composed of inorganic and other polymers. In composite materials, carbon ash and wood particle fully bonded, so ignite the process, because the silicon oxide, flame retardant material release $\mathrm{CO}$, the composite material is not easy to ignite.

\section{References}

1. Abu Bakar M B, Mohd Ishak Z A, Mat Taib R, et al.: 'Flammability and mechanical properties of wood flourfilled polypropylene composites', Journal of Applied Polymer Science, 116(2010) 2714-2722.

2. M. M. Barbooti, T. J. Mohamed, A. A. Hussain, F. O. Abas: 'Progress and prospect of fundamental fire research in China', Journal of University of Science and Technology of China, 36(2006) 1-8.

3. K. W. Chen: 'The Modulation Study of Emulsified Heavy Oil from Liquid Waste after Pyrolysis of Waste Rubber', Applied Mechanics and Materials, 529(2014) 45-48.

4. K. W. Chen: 'Energy Extraction from Carbon Ash Burning with Fluidized bed Gasifier', Applied Mechanics and Materials, 529(2014) 32-35.

5. K. W. Chen: 'Optimal manufacture formulas for solid fuel from barley husk after pyrolysis and lightweight building after its combustion utilization in sequence through statically analyses', J. Interdiscipl. Math.,17( 2014) 145-161. 